\title{
The Causal Effects of Parental Divorce and Parental Temporary Separation on Children's Cognitive Abilities and Psychological Well-being According to Parental Relationship Quality
}

\author{
Anna Garriga ${ }^{1} \cdot$ Fulvia Pennoni $^{2}$ D
}

Accepted: 6 July 2020 / Published online: 27 July 2020

(C) The Author(s) 2020

\begin{abstract}
We explore the effects of parental divorce and parental temporary separation on wellbeing of children at a specific stage of their development according to the parental relationship quality. Despite the importance of this subject, among previous studies only few consider very young children and are based on statistical methods properly tailored to enhance causal evaluations. We attempt to establish the effects on both cognitive abilities and psychological dimensions of children at age five by using data drawn from the first three waves of the UK Millennium Cohort Study. Using an appropriate imputation method, we apply the augmented inverse propensity treatment weighted estimator to infer causality. Overcoming some of the limitations of previous research, we find that the dissolution of high-quality parental unions has the most harmful effects on children, especially concerning conduct problems. We demonstrate the substantial variation on consequences of parental divorce depending on the level of parental relationship quality. We show that parental temporary separation is a type of family disruption that has significant negative effects on young children. In fact, we infer that they have more conduct and hyperactivity problems than children from stable or divorced families. Our results also suggest children to be targeted with appropriate policies aimed to reduce the adverse effect of family disruption.
\end{abstract}

Keywords Augmented inverse propensity treatment weighted estimator $\cdot$ Conduct problems $\cdot$ Family instability $\cdot$ Missing values

Electronic supplementary material The online version of this article (https://doi.org/10.1007/s1120 5-020-02428-2) contains supplementary material, which is available to authorized users.

Fulvia Pennoni

fulvia.pennoni@unimib.it

Anna Garriga

anna.garriga@upf.edu

1 Department of Political and Social Science, Pompeu Fabra University, Barcelona, Spain

2 Department of Statistics and Quantitative Methods, University of Milano-Bicocca, Milan, Italy 


\section{Introduction}

Parental divorce and union dissolution is an increasingly common experience for children in all developed countries. It has raised the debate on whether parental divorce is damaging for children's well-being and to what extent parents should remain together for the sake of the children. In accordance with this social concern, one of the most extensively discussed topics in the literature has been the average effects of divorce on children well-being. Many social surveys have been considered and various statistical methods have been used putting special emphasis on controlling for parental relationship quality and conflict prior to separation but often without considering that parental conflict does not always precede separation. In fact, a large percentage of low-distress couples divorce, a phenomena that has increased substantially in recent decades (Gähler and Palmtag 2015).

For this reason, some studies in the last two decades have offered a more nuanced explanation of the causality of divorce that focuses on the heterogeneity of divorce effects by parental relationship quality (Amato et al. 1995; Jekielek 1998; Hanson 1999; Strohschein 2005). They take into account in which way divorce affects different children, either positively or negatively, instead of concentrating on the average causal effect of divorce across the board (Amato 2010). These studies suggest that divorce may be a positive experience for children from high-distress marriages, while the dissolution of low-distress marriages may have opposite effects (Amato et al. 1995; Booth and Amato 2001). Despite the significant ramifications of these findings, to the best of the author's knowledge only few studies have examined the heterogeneity of the consequences of parental divorce by the level of parental relationship quality. These studies (for instance, see: Amato et al. 1995; Jekielek 1998; Hanson 1999; Morrison and Coiro 1999; Booth and Amato 2001; Strohschein 2005; Fomby and Osborne 2010; Yu et al. 2010; Kalmijn 2015) present the following characteristics: $a$ ) only two are based on non-US data, and only few use nationally representative samples or methods to infer causality; $b$ ) they have mainly analyzed children's psychological well-being while evidence on other children's outcomes such as cognitive development is scarce; $c$ ) the most of them focus solely on children in middle childhood or older. Amato (2010), in his most recent review of the literature, encourages more research concerning this issue. We use a national large sample with several cases of divorce and temporary separations among parents and cohabiting couples representing the current trend in the Western societies. We explore the effects both on the psychological well-being and cognitive development of the children. We investigate if and how these effects are different according to parental relationship quality. The latter is measured in a way to capture not only parental conflicts before separation but also communication, affection and emotions among the couple. We use the first three waves of the Millennium Cohort Study (MCS) which is a nationally representative longitudinal study of a cohort of British children born from 2000 to 2002 in the UK. We move forward from previous work and contribute in respect to the analysis of the interrelationships between family disruption, parental relationship quality and children's psychological well-being and cognitive development. First, we test whether the hypothesis of heterogeneity of divorce effects by parental relationship quality is also true for children from UK. Second, we aim to assess whether this hypothesis is also valid for young children since only Fomby and Osborne (2010) account for very young children and do not find evidence of heterogeneity of divorce by parental relationship quality. We have specifically focused on a salient period of children's lives, namely the transition to school. It is well-demonstrated that children who enter school without the necessary cognitive or socio-emotional skills have greater academic and behavioral difficulties during 
their school years and beyond than their more "school-ready" counterparts (Romano et al. 2010). Third, we aim to assess the heterogeneity hypothesis by improving and extending the methodological and analytical approach proposed in the literature. We focus on many of children's outcomes rather than just on one or two since we consider the following multiple dimensions of children's school readiness: three different cognitive abilities (verbal, problem-solving and spatial abilities) and five psychological dimensions (conduct, hyperactivity, internalizing and peer problems, and pro-social behavior). Unlike previous research on parental divorce, we use the Augmented Inverse Propensity Treatment Weighted (AIPTW, Robins et al. 2000) estimator in order to yield robust estimates of the effects of interest and an imputation method based on the statistical methodology of chained equations (Raghunathan et al. 2001), which allows us to jointly impute missing data for different types of variables. Furthermore, in previous research on the interplay between parental divorce, parental relationship quality and children's outcomes, the fact that a significant proportion of parents separate only temporarily was not considered. Little is known about the level of relationship quality of these parents before separation and the risks children experience when they face this type of family disruption (Kiernan et al. 2011; Nepomnyaschy and Teitler 2013).

In sum, by using cohort data similar to that used by Fomby and Osborne (2010), we aim to test the following three hypotheses: $i$ ) parental relationship quality and family disruption are unrelated processes that have independent effects on children (the independent hypothesis); $i$ ) the negative association between family disruption and children's well-being may be spurious because poor relationship quality is related to both family disruption and poor children well-being (the selection hypothesis); iii) the consequences of family disruption on children are contingent on the level of parental relationship quality experienced prior to this event (the heterogeneity hypothesis). To test this third hypothesis about the heterogeneity of the effects of family disruption by parental relationship quality is the main contribution of our study.

The paper is structured as follows. In Sect. 2 we provide a background section considering the effects of family disruption on children well-being, then we focus on the conceptual framework. In Sect. 3 we describe data and methods. In Sect. 4 we show the main results. In Sect. 5 we provide a discussion. The supplementary material provides further details on data, missing data imputation and additional tables with results.

\section{Background}

\subsection{Family Disruption on Children Well-being}

Studies on the effects of parental divorce on children's well-being that use ordinary least squares (OLS) and logistic models show that part of this effect is spurious and it is only partially explained by parental relationship quality (Hanson 1999). Since the late 1990s, several studies have used more innovative research designs to identify the independent effects of parental divorce and father absence such as lagged dependent variable models, growth curve models, individual and sibling fixed effects models, natural experiments and instrumental variables, and propensity score matching. McLanahan et al. (2013) review these studies and find consistent evidence that parental divorce exerts negative effects on the well-being of offspring. They also show that this evidence is stronger for children's 
socio-emotional development, especially in externalizing problems, than for children's cognitive ability. Nevertheless, they present the following features: $a$ ) most studies of the effect that of parental divorce on cognitive and psychological development are based on US samples $b$ ) very few studies focus on children who experience parental divorce in early childhood, and $c$ ) only one (Strohschein 2005) explores the heterogeneity of divorce effects by the quality of the parental relationship prior to separation.

A weakness of existing research is that it does not consider parents who separate only temporarily. Recent studies observe that a non-negligible proportion of parents separate for a short time period and then re-partner with the same person (Kiernan et al. 2011; Nepomnyaschy and Teitler 2013). However, as stated by Nepomnyaschy and Teitler (2013, 3) 'in most studies, this family 'type' is usually classified as either intact or separated (depending on when cohabitation status is ascertained), but it may differ in many respects from both of those groups". The reason this type of family disruption is scarcely considered in previous research is that most studies only use two waves of survey data, and at least three waves are necessary to detect it. The existing research on the characteristics of parents who only separate temporarily show that such couples have a more disadvantaged socio-demographic background than with continuously intact relationships (Kiernan et al. 2011; Nepomnyaschy and Teitler 2013). Despite that, the only two studies that analyze the consequences of temporary separation on children well-being find evidence of a negative effect, even when controlling for several socio-demographic characteristics (Kiernan et al. 2011; Nepomnyaschy and Teitler 2013). However, no study controls for the relationship quality of parents before separation and some evidence suggest that couples who separate temporarily have a lower relationship quality than stable couples long before separation occurs (Vennum et al. 2014). Thus, if poor parental relationship quality may cause temporary separation, then it is difficult to rule out the possibility that the negative association between parental temporary separation and children's outcomes may be due to relationship quality rather than this event per se.

\subsection{Heterogeneity of the Effects of Parental Divorce by Parental Relationship Quality}

\subsubsection{Conceptual Framework}

Two main explanations are provided regarding the heterogeneity of the effects of parental divorce ${ }^{1}$ by parental relationship quality. One is the stress relief hypothesis (Wheaton 1990) which concerns the consequences of transitions in life roles. Wheaton $(1990,210)$ stated that “...instead of being stressful, life events may at times be either non-problematic or even beneficial, offering escape from a chronically stressful role situation, creating the apparent paradox of more 'stress' functioning as stress relief'. According to this perspective, the stressful event of parental divorce may be beneficial for children whose parental relationship prior to divorce has been poor, as it takes them away from an aversive and stressful home environment. After divorce, these children should enjoy an improvement

\footnotetext{
1 We are only able to empirically study the heterogeneous effects of parental divorce and not the heterogeneous effects of parental temporary separation due to data limitations. For this reason, we only theoretically discuss the heterogeneous effects of parental temporary separation in this section. In addition to that, the literature does not provide any theoretical explanation about the heterogeneity of the effects of parental temporary separation.
} 
in their well-being since they no longer experience the parental conflict (Booth and Amato 2001; Strohschein 2005).

By contrast, the dissolution of low-distress parental relationships may be detrimental to children's development. Children from relatively harmonious families may not benefit from divorce, since it is unlikely that they experience this event as stress relief. For these children, divorce may instead give rise to stressful situations such as a decline in their standard of living, moving to a poorer neighborhood, changing schools, and losing contact with the non-custodial parent (Amato 2010). Children from non-dysfunctional families may also begin to experience parental discord after separation, since issues such as custody, childrearing, visitation, and child support are potentially conflictual (Booth and Amato 2001).

In addition to changes in stress, children's understanding and perceptions of divorce depend on the level of their parents' pre-divorce relationship problems, another factor related to children's adjustment after separation. Children who have witnessed parental disputes may anticipate their parents' divorce and attribute it to external reasons, such as parental conflict, as argued by Booth and Amato (2001). For children from low-distress families, by contrast, divorce might come as more of a surprise and they might see divorce as a threat to their happiness. Booth and Amato (2001) give possible reasons as to how an unexpected divorce may adversely impact on children. First, for these children, it is more difficult to comprehend and accept the reasons for their parents' separation. As Maes et al. (2012, 276) state: "if children do not understand why their parents have divorced, they make up their own story around things they do know, increasing the danger that children will blame themselves". Second, children who do not anticipate parental divorce may feel that they have little control over events in their lives (Booth and Amato 2001). Children's self-blame and locus of control are, in turn, negatively related to their adjustment after divorce (Bussell 1996; Kim et al. 1997).

Are these useful in explaining the heterogeneity of parental divorce for infants and very young children? The explanation of children's understanding and perceptions of divorce is unlikely to be valid for very young children due to the kind of reasoning needed for children to be able to anticipate this event and blame themselves for it. The stress relief explanation developed for older children and adults, however, can also be applied to infants and very young children. There is a growing and consistent body of research documenting that the exposure to poor parental relationship quality during infancy affects children's wellbeing cross-sectionally during infancy and longitudinally during their pre-school years (Fitzgerald 2010; Graham et al. 2013; Zhou, Cao and Leerkes 2017). For example, a possible mechanism is that parental conflict experienced by infants is associated with neural responses to emotional tone of voice, particularly very angry speech (Graham et al. 2013). With the existing evidence, it is reasonable to assume that if parental conflict produces stress in infants, then when parental divorce occurs this source of stress will disappear and their well-being will improve.

The second explanation does not focus on the consequences of direct exposure of infants to parental conflict but highlights an indirect pathway through parental well-being: parental relationship quality moderates the effect of parental divorce on very young children because parental relationship quality also moderates the effect of divorce on parent's wellbeing. To our knowledge, this explanation has not been mentioned by previous research and is based on two main premises. First, it has been largely demonstrated that parents' emotional adjustment after divorce is an important predictor of children's well-being (Amato 1993) and that parents' emotional problems are also clearly associated with adverse children's outcomes during infancy and early childhood (Petterson and Albers 2001; Kiernan and Huerta 2008). In addition to that, few empirical studies that have focused on this topic 
predominantly show that people who enjoyed a high relationship quality prior to divorce suffer the most harmful negative effects on their emotional well-being (for instance, see Wheaton 1990; Booth and Amato 2001; Williams 2003; Waite et al. 2009; Ye et al. 2017). For people with low levels of relationship quality, the findings are mixed. Some studies give support to the hypothesis that divorce is beneficial for the emotional well-being of people in highly conflictual or unsatisfactory relationships (for instance, see: Wheaton 1990; Williams 2003; Amato and Hohmann-Marriott 2007; Ye et al. 2017). Others find evidence that when people divorce from an unsatisfactory relationship, they experience a decrease in their emotional well-being but to a lesser extent than those who divorce from satisfactory relationships (Kalmijn and Monden 2006; Waite et al. 2009). For these reasons, it seems plausible to hypothesize that if divorce has the most harmful effects on parents who enjoyed a high level of relationship quality, their children would also experience the most harmful effects of this event.

\subsubsection{Previous Research}

To the extent of our knowledge the current research is based on the possible data according to the characteristics of the sample at the time and on the best method of analysis. Confidence in research findings increases when studies are based on a nationally representative sample with a large sample size. Some studies have less than 300 cases in the divorce group, and only three (Hanson 1999; Strohschein 2005; Kalmijn 2015) use nationally representative surveys. The majority of samples are based on American children, with the exception of Kalmijn (2015) and Strohschein (2005), and there is not enough evidence to conclude the hypothesis of heterogeneity of divorce effects is valid in all Western countries or if this hypothesis is country-specific. With exception of Fomby and Osborne (2010), all relevant studies examine only children whose parents are married; they exclude the large and increasing proportion of children who are living with their biological cohabiting parents (Kiernan et al. 2011).

Concerning the characteristics of the outcomes and focal variables we observe that seven of the nine studies in this field used the psychological well-being of offspring; there is less consistent evidence of variation in divorce effects in other important outcomes. Among studies concerning the heterogeneity of divorce, only one focus on educational achievement (Hanson 1999). For this reason, with the existing research, it is not possible to say whether the hypothesis about the heterogeneity of divorce effects is valid for most children's outcomes, or only for psychological ones.

In addition, existing research does not focus on a specific stage of children's development. Instead, samples are used with great variation in the children's ages at the time of divorce, and the age when response variables are measured. Most studies look at children who experienced parental divorce over a wide range of ages (Booth and Amato 2001; Hanson 1999; Kalmijn 2015). In some of them, divorce occurred any time from when the children were born to when they were adults. Only Fomby and Osborne (2010) focus on a specific stage of children's development namely parental divorce that occurs before age 3 , and the response variable is measured at age 3 . Second, as mentioned, studies finding evidence in favor of the heterogeneity hypothesis analyze children's outcomes measured during middle childhood and/or adolescence (Hanson 1999; Jekielek 1998; Morrison and Coiro 1999; Strohschein 2005) or adulthood (Amato et al. 1995; Booth and Amato 2001; Yu et al. 2010; Kalmijn 2015) and the only paper that does not support this hypothesis focuses on outcomes in very young children (Fomby and Osborne 2010). These contradictory 
results may suggest that the effects of divorce only vary by parental relationship quality for children in middle childhood or older. However, with only one study on very young children, there is not enough evidence to conclude whether divorce effects are heterogeneous depending on the age of the child at the time of divorce and/or the age when the outcomes were measured.

\section{Materials and Methods}

\subsection{Data}

The data correspond to the first three waves of Millennium Cohort Study (MCS) which is a high-quality profile survey representative for the UK (Plewis et al. 2000; Hansen and Joshi 2007; Plewis 2007; Hansen et al. 2012). The first sweep was carried out between September 2000 and January 2002. It contains information on 18,819 babies from 18,533 families, collected from the parents when the babies were 9-11 months old. The families were contacted again when the children were aged 3 and 5 years. The response rates achieved for the second (2004/05) and third (2006) waves were 78\% and 79\% of the target sample, respectively. More than two-thirds of the sample (around 69\% representing 13,234 families) responded in all three waves (Ketende 2010). The MCS sample design allowed for over-representation of families living in areas with high rates of child poverty and/or high proportions of ethnic minorities. Survey methods were used to take account of the initial sampling design, and adjustments were made for non-response in the recruitment of the original sample and sample attrition over the follow-up period to age five. ${ }^{2}$

We consider children whose family structure is available for all the first three waves of the MCS. The sample includes only singleton children and families where the mother is the main respondent at the first wave. More details on the data and on how we handle missing values are available in Section A1 of the supplementary material.

\subsection{Variables}

\subsubsection{Response Variables}

The variables of interest for school readiness are measured when children are 5 years old, at the third wave. The Strengths and Difficulties Questionnaire (SDQ) (Goodman 1997) assesses children's behavioral adjustment and is answered by the mother. The SDQ is made up of five subscales assessing emotional symptoms, conduct problems, hyperactivity or inattention problems, peer problems, and pro-social behavior. Each subscale has five items with scores ranging from 0 to 2. Children's cognitive development is assessed by using the British Ability Scales (BAS II) (Elliott et al. 1997). The following BAS subscales were used to measure different domains of cognitive development: the naming vocabulary test, which assesses expressive language; the picture similarities test, which measures pictorial reasoning; and the pattern construction test, which assesses spatial ability. These

\footnotetext{
${ }^{2}$ Details on the survey, its origins, objectives, and sampling, as well as the content of the survey waves, are contained in the documentation attached to the data deposited at the UK Data Archive at Essex University.
} 
Table 1 Descriptive statistics of the children's outcomes according to the family situation

\begin{tabular}{|c|c|c|c|c|c|c|c|}
\hline \multirow[t]{2}{*}{ Outcomes } & \multicolumn{2}{|l|}{$\mathrm{SF}$} & \multicolumn{2}{|l|}{$\mathrm{PtS}$} & \multicolumn{2}{|l|}{ PD } & \multirow[t]{2}{*}{$\mathrm{N}$} \\
\hline & Mean & $\mathrm{SD}$ & Mean & SD & Mean & SD & \\
\hline \multicolumn{8}{|l|}{ Psychological dimensions } \\
\hline Conduct problems & 1.29 & 1.33 & 1.75 & 1.56 & 1.83 & 1.63 & 9860 \\
\hline Hyperactivity problems & 3.00 & 2.22 & 3.60 & 2.44 & 3.82 & 2.44 & 9564 \\
\hline Internalizing problems & 1.29 & 1.47 & 1.54 & 1.79 & 1.52 & 1.64 & 9760 \\
\hline Peer problems & 1.04 & 1.30 & 1.46 & 1.57 & 1.35 & 1.40 & 8916 \\
\hline Pro-social behavior & 8.44 & 1.58 & 8.20 & 1.67 & 8.33 & 1.69 & 9870 \\
\hline \multicolumn{8}{|l|}{ Cognitive dimensions } \\
\hline Vocabulary test & 36.25 & 10.67 & 32.16 & 10.60 & 33.77 & 9.80 & 10,327 \\
\hline Pattern construction test & 31.63 & 9.68 & 30.28 & 9.14 & 29.52 & 9.99 & 10,314 \\
\hline Picture similarity test & 36.01 & 9.83 & 35.68 & 10.57 & 34.62 & 9.80 & 10,293 \\
\hline
\end{tabular}

SF is Stable Family, PtS is Parental temporary Separation and PD is Parental Divorce. The score ranges from 0 to 10 for the psychological variables and from 0 to 60 for the variables related to the cognitive abilities

were conducted by an interviewer at home. The three tests assess the three most significant information-processing skills: verbal reasoning, non-verbal reasoning and spatial abilities (Hill 2005). A standardized score is computed for each cohort member according to his/her age band considered every three months. Table 1 shows the average scores for the response variables stratified according to the family situation at age 5 as defined in the following section. Children experiencing parental temporary separation or parental divorce shows lightly more psychological problems and lower scores for cognitive development with respect to children with stable family.

\subsubsection{Focal Variables}

We use the first three waves of the survey to create the following main family situations: children that experience parental divorce are those whose parents were together (married or cohabiting) until they were at least 9 months old, but who divorced when they were aged between 9 months and 5 years $(\mathrm{N}=1177)$; children that experience parental temporary separation are those whose parents were together (married or cohabiting) when they were born and when they were 9 months and 5 years old $(\mathrm{N}=277)$; however, on one or more occasions, their parents spent more than one month living apart; children in stable families are those whose parents remained in stable married or cohabiting unions from their birth until age $5(\mathrm{~N}=9001)$.

Partnership quality was derived from the Golombok Rust Inventory of Marital State (GRIMS, Rust et al. 1990) which is a psychometric instrument for the assessment of marital discord and the overall quality of a couple's relationship. We only used the GRIMS scale for responses from the mother, as the fathers' questionnaire showed a high percentage of missing cases. We use this scale at the first wave (9 months) since it has seven items, as opposed to four items in the subsequent waves.

The following four items, the responses to which were collected at the first wave assess the negative aspects of relationship quality: (1) "my partner doesn't seem to listen to me"; 
(2) "sometimes I feel lonely even when I am with my partner"; (3) "I wish there was more warmth and affection between us"; and (4) "I suspect we may be on the brink of separation". The other three items assess the positive aspects of relationship quality: (1) "my partner is usually sensitive to and aware of my needs"; (2) "our relationship is full of joy and excitement"; and (3) "we can always make up quickly after an argument". The item responses consist of the following: strongly agree (0); agree (1); neither agree nor disagree (2); disagree (3); strongly disagree (4) and can't say (5). "Can't say" responses were considered as missing information. To create an ordinal scale, we included both the positive and the negative items, which involved reversing the answers to the positive items. For these items the answers were: strongly disagree (0); disagree (1); neither agree nor disagree (2); agree (3); strongly agree (4). We then added up respondents' answers to the seven items, which produced a scale with a minimum of 0 and a maximum of 28 .

Most studies, also due to few observed divorced couples, consider the heterogeneity of divorce by accounting for an interaction between parental divorce and the continuous variable measuring parental relationship quality. They assume that the magnitude and sign of the interaction effect is the same across any value of the relationship quality and they do not allow the extent to which the effect of parental divorce diverges in according to the intensity of the relation to be examined. Only Fomby and Osborne (2010) use a binary variable to identify couples with a low relationship quality if the reported value is below the 25th percentile of the sample distribution. We consider the quartiles of the empirical distribution and we account for the following ordered categories of decreasing union quality: very good, good, poor and very poor. We choose this specification to obtain a more accurate portrayal of children who experience especially poor and very poor parental relationship quality.

Table 2 shows the descriptive statistics of the family situation according to parental relationship quality. In the sample $86 \%$ belong to stable family, $11 \%$ experience parental divorce and around $3 \%$ experience parental temporary separation. The percentages of those reporting different levels of relationship quality are quite similar: $28 \%$ and $20 \%$ reported high and low quality relationships, respectively. The data reveal that parents who remained together from wave 1 (children were 9 months old) to wave 3 (children were 5 years old) had better relationship quality on average than those who divorced or experienced some period of separation. Comparing the two types of family disruption, parents who subsequently divorce exhibit worse relationship quality than those who only temporarily separate. At wave 1, around $18 \%$ of parents in stable family reported the lowest relationship quality compared with $32 \%$ of those who later separated temporarily and $39 \%$ of those who later divorced. Hence, in accordance with the selection hypothesis, a large number of children with divorced parents were exposed to poor union quality before parental separation. However, contrary to this hypothesis, Table 2 also shows that a considerable proportion of parents who divorced had not experienced poor relationship quality prior to ending their relationship. Among children whose parents divorced, around $17 \%$ and $22 \%$ belonged to families with the highest $\left(\mathrm{q}_{1}\right)$ and high $\left(\mathrm{q}_{2}\right)$ relationship quality, respectively. It is important to acknowledge that children whose parents had the highest relationship quality at wave 1 could experience poor parental relationship quality after this wave and prior to their parents' divorce since this event occurs between wave 1 and wave 3 of the survey.

Although the percentages show that a large proportion of divorced parents reported the lowest level of relationship quality before separation, the row percentages demonstrate that the majority of parents with poor-quality relationships do not separate. Approximately three-quarters $(73 \%)$ of mothers with the lowest level of relationship quality at wave 1 remained in a relationship with the father of their child four years later. 
Table 2 Descriptive statistics of the family situation according to the levels of the parental Relationship Quality (RQ)

\begin{tabular}{|c|c|c|c|c|}
\hline Relationship quality & SF & PtS & PD & Total \\
\hline \multicolumn{5}{|l|}{ RQ ( $q_{1}$ very good) } \\
\hline $\mathrm{N}$ & 2987 & 69 & 201 & 3257 \\
\hline$\%$ row & 91.71 & 2.12 & 6.17 & 100.00 \\
\hline$\% \mathrm{col}$ & 33.19 & 24.91 & 17.08 & 31.15 \\
\hline \multicolumn{5}{|l|}{ RQ ( $q_{2}$ good $)$} \\
\hline $\mathrm{N}$ & 2634 & 66 & 258 & 2958 \\
\hline$\%$ row & 89.05 & 2.23 & 8.72 & 100.00 \\
\hline$\% \mathrm{col}$ & 29.26 & 23.83 & 21.92 & 28.29 \\
\hline \multicolumn{5}{|l|}{$\mathrm{RQ}\left(\mathrm{q}_{3}\right.$ poor $)$} \\
\hline $\mathrm{N}$ & 1785 & 52 & 254 & 2091 \\
\hline$\%$ row & 85.37 & 2.49 & 12.14 & 100.00 \\
\hline$\%$ col & 19.83 & 18.77 & 21.58 & 20.00 \\
\hline \multicolumn{5}{|l|}{ RQ ( $q_{4}$ very poor) } \\
\hline $\mathrm{N}$ & 1595 & 90 & 464 & 2149 \\
\hline$\%$ row & 74.22 & 4.19 & 21.59 & 100.00 \\
\hline$\%$ col & 17.72 & 32.49 & 39.42 & 20.55 \\
\hline \multicolumn{5}{|l|}{ Total } \\
\hline $\mathrm{N}$ & 9001 & 277 & 1177 & 10,455 \\
\hline$\%$ row & 86.09 & 2.65 & 11.26 & 100.00 \\
\hline
\end{tabular}

SF is Stable Family, PtS is Parental temporary Separation and PD is Parental Divorce

Overall, considering only values from Tables 1 and 2, we cannot say whether the observed differences on school readiness between children from different family situations are explained by differences in parental relationship quality pre-dating the experience of family disruption.

\subsubsection{Control Variables}

The control variables illustrated in Table 3 are measured when children were 9 months old (wave 1), namely before parental separation took place, and took into account several socio-demographic characteristics related to family disruption and children's well-being (Booth and Amato 1991, 2001; Wilson and Waddoups 2002; Amato and Hohmann-Marriott 2007; Kiernan and Huerta 2008; Brown 2004; Kiernan and Mensah 2009; BrooksGunn et al. 2010; Muluk et al. 2014; Idstad et al. 2015; Karraker and Latham 2015; Oláh and Gähler 2014; Sabates and Dex 2015).

Concerning the social exchange theory (Levinger 1976) we include into the rewards and costs the following variables to control for the selection into family disruption: family income, housing tenure, mother's educational attainment and ethnicity, mother's health (depression and longstanding illness) and the presence of half- or step-siblings at home. We consider the following variables as barriers to family disruption: paid work status of the mother; whether the mother lived with someone else as a couple before living with the father of the child; type of parental union (married directly, cohabitation before marriage, or cohabitation); year that parents began living together as a couple; whether parents grew 


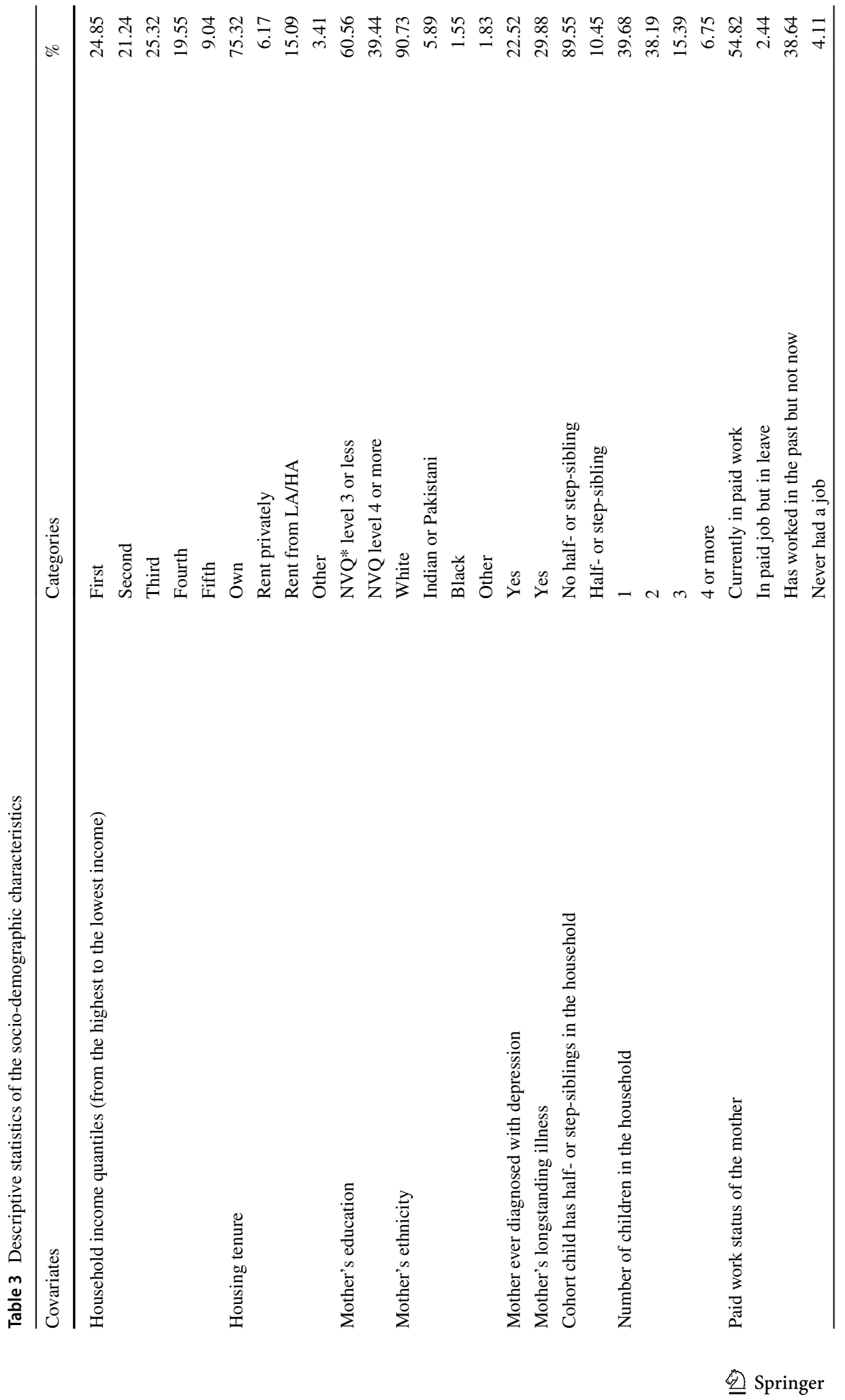




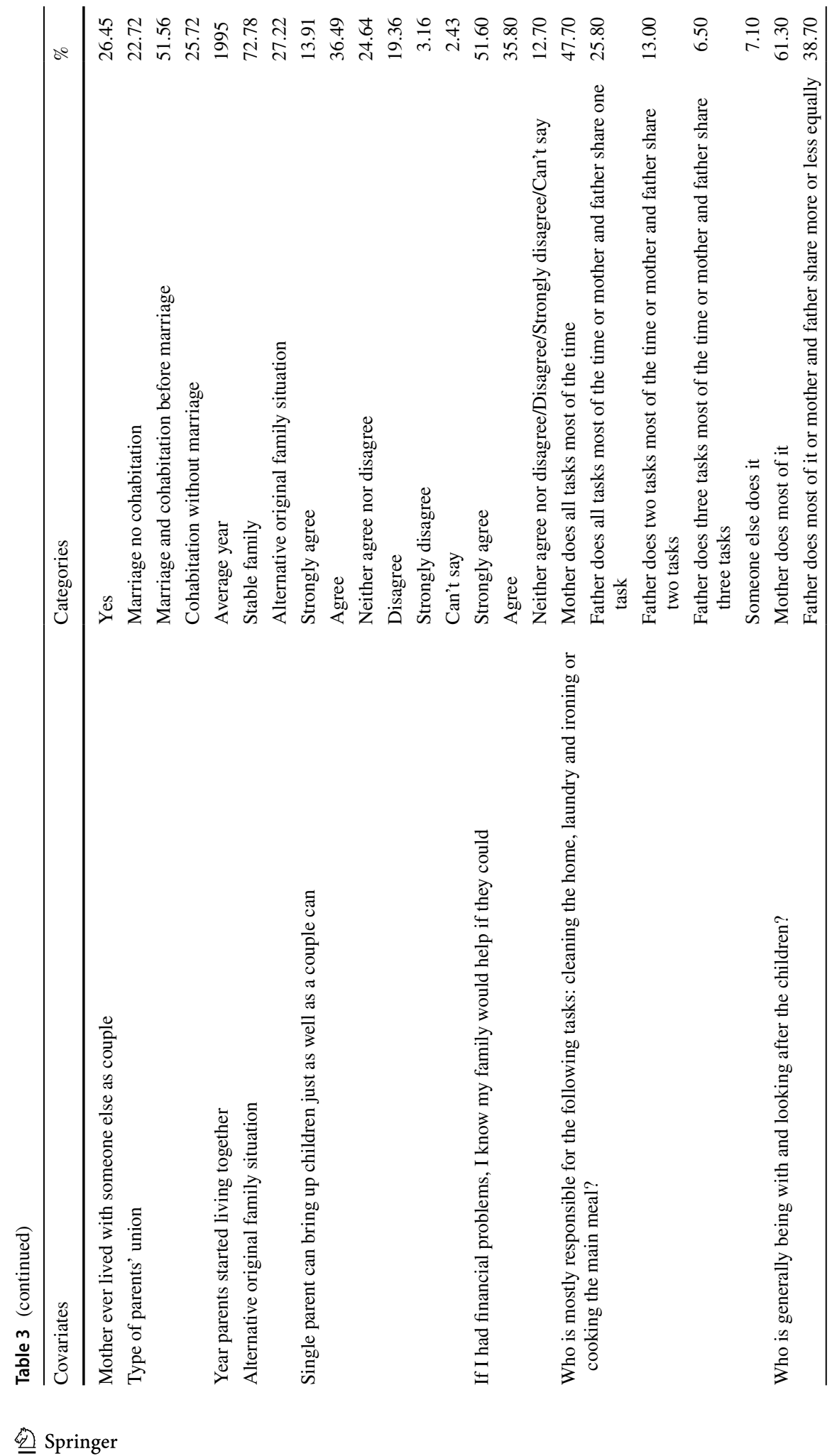




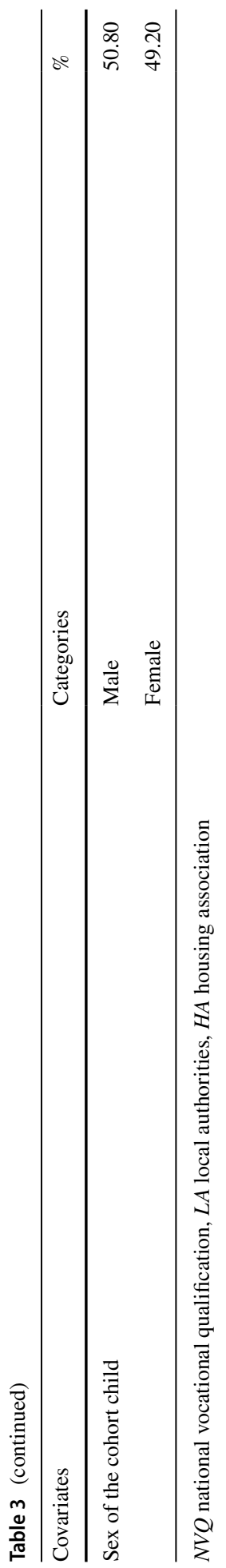


up in a non-stable family and mother's attitudes to single-parent upbringing. Instrumental support is measured by the following response provided by the mother: "If I had financial problems, I know my family would help if they could". Finally, another group of control variables is related to the division of unpaid work, which is associated with the probability of divorce: who is mostly responsible for household tasks and who is generally with and looking after the children.

\subsection{Methods and Analytical Strategy}

The effect of parental divorce (or parental temporary separation) on children's outcomes is evaluated under the framework of counterfactual reasoning or Potential Outcomes (POs) (Rubin 1974, Holland and Rosenbaum 1986). In this context, we are interested to estimate the Average Treatment Effect (ATE) that is conceived as the difference between the expected values of the POs of the children in the treated and untreated condition. We refer to the POs of individual exposed to treatment as $Y_{i}^{(1)}$ and not exposed as $Y_{i}^{(0)}$ for each $i$, $i=1, \ldots, n$. The treatment is provided only to a fraction of the units, and it is denoted by a binary variable $Z_{i}$ that is equal to 1 if the individual $i$ is treated and to 0 if he/she is not treated. The treatment effect is defined as the difference $Y_{i}^{(1)}-Y_{i}^{(0)}$ and the same value over the population is the ATE defined as the expected value of the POs as follows

$$
\mathrm{ATE}=\mathrm{E}\left[Y_{i}^{(1)}-Y_{i}^{(0)}\right] .
$$

The realized outcome for individual $i$ is given by

$$
Y_{i}=Z_{i} Y_{i}^{(1)}+\left(1-Z_{i}\right) Y_{i}^{(0)}
$$

In this framework, the outcomes of the children whose parents are divorced or temporary separated are only observed in the presence of the treatment conditions and the outcomes of the children in stable families are only observed in the absence of treatment. That is, a child can experience parental divorce or can live in a stable family from 9 months to age 5. As recently stated by Kim (2011) the ATE joints the realized developmental outcomes for children had experienced divorce or temporary separation and the counterfactual outcomes for these children had their parents remained together. The effects of family disruption on children's outcomes can be assessed only on average in this non-experimental study, since each child belongs to one of the treatment or to the control group and one PO is always not realized. Children experiencing family disruption may be not randomly selected, and the family characteristics that determine the disruption may also affect the child's well-being through other pathways (McLanahan et al. 2013).

The Propensity Score (PS, Rosenbaum and Rubin 1983) is a multivariate statistical matching method proposed for data collected in non-experimental contexts aimed to reduce the bias of the estimator of the treatment effect by considering the observed pretreatment covariates (Rosenbaum 2020). The PS concerns the conditional probability of the treatment (the probability of experiencing parental divorce or parental temporary separation) given the observed pre-treatment covariates. This aims to mimic an experimental context especially when the observational data are rich as in the context of this application where similar questionnaires are administered to the participants. For estimating the ATE the weighted regression estimator (Rosenbaum 1987) defined as the Inverse Propensity Treatment Weighted (IPTW) estimator (Robins et al. 2000) weights each unit according to the estimated inverse probability of receiving the treatment actually received. The weights 
are obtained as the inverse of the estimated PS and in this context they allow us to compare children exposed to divorce despite their low probability of exposure and children not-exposed to divorce. We use observable pre-treatment covariates collected into the column vector $\boldsymbol{X}_{i}$ whose realized values are denoted with $\boldsymbol{x}_{i}$ for $i=1, \ldots, n$. We assume that conditional to the pre-treatment covariates the average outcomes in the treated and control groups in the absence of treatment would be the same. Another assumption is defined as strong ignorability (Rosenbaum and Rubin 1983) and postulates that given the pre-treatment covariates the treatment choice is independent of the POs. The positivity assumption is also required meaning that each treatment level occurs with some positive probability. This is also defined overlap assumption since it implies that the support of the conditional distribution of the covariates $\boldsymbol{x}_{\mathrm{i}}$ given $Z_{i}=0$ overlaps completely with the conditional distribution of $x_{\mathrm{i}}$ given $Z_{i}=1$ (Imbens and Wooldridge 2009).

Disposing of a sample of $n$ independent units, the IPTW estimator uses weights estimated through the maximum likelihood estimates of the parameters of the multiple logistic regression model given by

$$
\hat{w}_{i}=\frac{1}{\hat{p}\left(z_{i}=1 \mid x_{i}\right)}, \quad i=1, \ldots, n .
$$

In this way it is possible to mimic a pseudo-population in which the covariates are balanced between treated and untreated individuals. The Augmented IPTW (AIPTW) estimator has the smallest asymptotic variance among the class of the IPTW estimators (Robins et al. 1994) and it is obtained according to the proposal of Lunceford and Davidian (2004) as follows:

$$
\hat{\tau}_{\text {aiptw }}=\frac{1}{n} \sum_{i=1}^{n} \frac{Z_{i} Y_{i}}{\hat{p}\left(z_{i}=1 \mid \boldsymbol{x}_{i}\right)}-\frac{1}{n} \sum_{i=1}^{n} \frac{Z_{i}-\hat{p}\left(z_{i}=1 \mid \boldsymbol{x}_{i}\right)}{\hat{p}\left(z_{i}=1 \mid \boldsymbol{x}_{i}\right)} \hat{f}\left(Y_{i}=y_{i} \mid \boldsymbol{v}_{i}\right),
$$

where $\hat{f}\left(Y_{i}=y_{i} \mid v_{i}\right)$ denotes the multiple linear regression model estimated for the observed responses by using ordinary least squares or robust inferential methods with $v_{i}$ denoting the vector of the observed covariates. All the relevant covariates should be included in the sets $\boldsymbol{x}_{i}$ and $\boldsymbol{v}_{i}$. We propose to apply the AIPTW estimator since it corrects for possible mis-specifications in the PS model or in POs model and it is statistically more robust with respect to other methods. The so-called "double robustness" property (Bang and Robins 2005; Neugebauer and van der Laan 2005) implies that the estimator remains consistent if the POs or PS model are incorrectly specified, see among others, Cao et al. (2009) and Glynn and Quinn (2010). When the estimated weights are too large Robins et al. (2000) propose to truncate such weights up to a specified threshold, preventing to some units being highly influential.

The analytical strategy we follow is to consider the three hypotheses illustrated in the introduction and to show the results according to the following steps. First, we estimate the ATEs of parental divorce and parental temporary separation including the available covariates in the PS model shown in Table 3 and accounting also for the overall weights to consider attrition and the initial sampling design. We estimate the POs model by considering all the variables most directly related to the children's living conditions selected according to the knowledge in the field. They are the following: sex of the child; number of children at home; mother's education, ethnicity and labor force participation; household income; housing tenure; mother's longstanding illness and depression, and type of parental union. Second, to evaluate the selection hypothesis we estimate the ATE including the 
parental relationship quality in the POs and PS models. Third, to evaluate the heterogeneity for parental divorce we estimate the ATE by considering the quartiles of the variable relationship quality in the POs and PS models. The heterogeneity hypothesis is not considered for children experiencing parental temporary separation. The three steps are repeated for every outcome by considering each time five imputed datasets in order to account for missing values. More details are provided in Section A1 of the supplementary material.

\section{Results}

\subsection{Average Effects of Family Disruption on Children's Well-being}

In order to evaluate $i$ ) the independent and ii) the selection hypotheses, we compare the following two models: Model 1, which only includes control variables, and Model 2, which also considers parental relationship quality in both outcome and treatment models. Table 4 reports the results for each psychological and cognitive dimension. As expected, this covariate is significant in predicting the probability of parental divorce and parental temporary separation for each dimension. We refer to Section A2 of the supplementary material for some additional results for conduct problems where we show the estimated regression coefficients of the covariates included in the PO and PS models (Table A1 and A2, respectively). Concerning the results showed in Table 4 we notice that the estimated ATE of parental divorce is significant for all the psychological dimensions and except for the picture similarity test in Model 1 for all the other cognitive dimensions. However, when parental relationship quality is introduced among the control variables (Model 2), the effect of parental divorce is not significant for internalizing problems and peer problems. For conduct and hyperactivity problems, the magnitude of the effect of parental divorce is still significant but is considerably reduced. For conduct problems, parental divorce increases the average score of 0.244 points (Model 1) with respect to the score of children in stable family but this average score decreases to 0.162 when parental relationship quality is included (Model 2). For hyperactivity, the effect of parental divorce is 0.407 in Model 1 and 0.241 in Model 2. By considering parental relationship quality the ATE is reduced of around $34 \%$ for conduct problems and around $41 \%$ for hyperactivity problems ${ }^{3}$. Unexpectedly, the effect of parental divorce on pro-social behavior becomes significant in Model 2. For the cognitive dimension, the estimated effect of parental divorce in Model 1 is significant for all cognitive variables with the exception of the picture similarity test. Unlike the results for the most psychological variables, when parental relationship quality is included (Model 2), the effect of parental divorce does not decrease for the pattern construction test, and even increases slightly for the vocabulary test.

The effect of parental temporary separation is not significant in any model for internalizing, peer problems and pro-social behavior. In contrast, parental temporary separation has a significant negative effect on children's hyperactivity and conduct in both models. For parental divorce, parental relationship quality does not reduce the effect of parental temporary separation in any of these psychological dimensions. It is also important to point out that for conduct and for hyperactivity problems, the magnitude of the effect of parental

\footnotetext{
3 These percentages are calculated by considering the estimated ATE multiplied by 100 and divided by the estimated PO referred to stable family.
} 


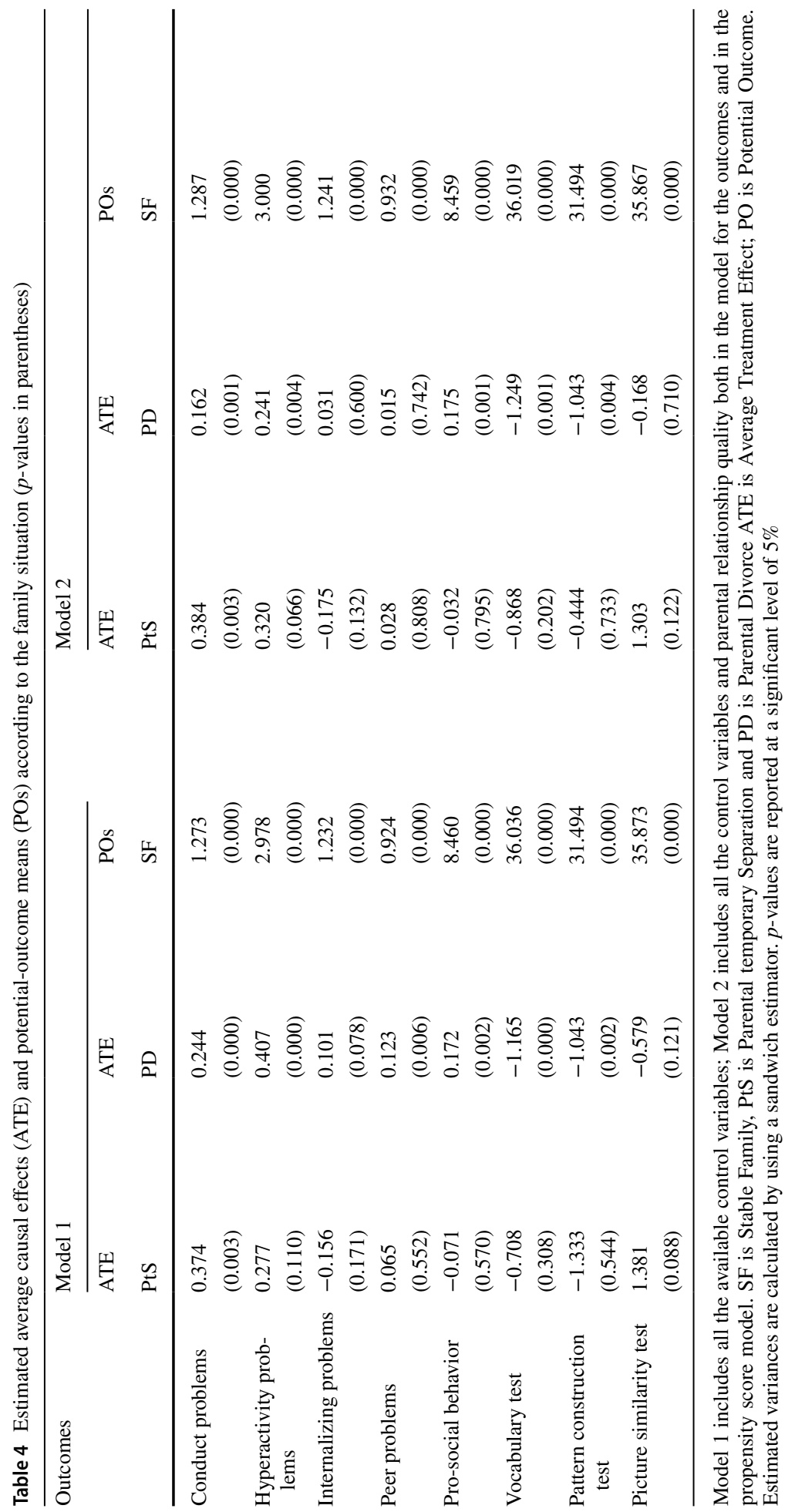


temporary separation is greater than the effect of parental divorce. The results of Model 2 show that the estimated PO mean for the conduct scores of children in stable family is 1.287. Parental temporary separation increases this score by an average of 0.384 while parental divorce increases it by an average of 0.162 . In other words, the effect of parental temporary separation increases conduct problems by around $30 \%$ while parental divorce only increases conduct problems by around $16 \%$. Similar differences result for hyperactivity problems. Turning to cognitive variables, the effect of parental temporary separation is not significant in any model for the pattern construction and vocabulary tests and this effect is only significant in Model 1 for the picture similarity test.

\subsection{Heterogeneous Effects of Parental Divorce According to Parental Relationship Quality}

The third hypothesis is evaluated according to the results showed in Table 5 reporting the ATE estimated according to the relationship quality. With regard to the psychological dimension, the effect of parental divorce on conduct problems is only significant for children that experienced extreme levels of parental relationship quality. Among children whose parents reported the highest relationship quality $\left(\mathrm{q}_{1}\right)$, the PO mean in stable family is 0.960 , with parental divorce increasing it by 0.349 . In other words, children with parental divorce experiencing good relationship quality show more conduct problems than children in stable family. The difference in percentage is lower among children whose parents had a very poor relationship quality $\left(\mathrm{q}_{4}\right)$.

For hyperactivity problems, the effect of parental divorce is significant only for those whose parents had a very poor relationship. Children with parental divorce experiencing very poor relationships among parents, have a higher probability of reporting hyperactivity problems compared to children with a stable family; the difference in percentage is around $11 \%$.

As it can be seen, for internalizing problems the average effect of parental divorce is not significant once parental relationship quality is considered. However, when this effect is analyzed according to the quartiles of parental relationship quality, we get similar results to those obtained for conduct problems. The effect of parental divorce is significant in the extreme level of the relationship quality: within the group of children whose parents showed very good relationships, those who experience parental divorce have a higher probability of manifesting internalizing problems compared to children from stable family; the difference in percentage is around $20 \%{ }^{4}$. Within the group of children whose parents had very poor relationships, the difference in percentage is lower, at around $12 \%$. For peer problems, the effect of parental divorce is only significant for children whose parents had a good relationship $\left(\mathrm{q}_{2}\right)$ and, for pro-social behavior, the effect is only significant for those with bad relationships $\left(\mathrm{q}_{3}\right)$.

With regard to the cognitive dimension of children's school readiness, although the average effect of parental divorce on the picture similarity tests is not significant Table 4, the results are different in Table 5. The effect of parental divorce is significant and equal to -1.326 among children with parents reporting very poor relationships $\left(\mathrm{q}_{4}\right)$. The effect for those experiencing very good relationships $\left(\mathrm{q}_{1}\right)$ among parents is not significant. For the vocabulary test, it is interesting to note that the estimated ATE is significant and negatively large for those children exposed to a very good relationship $\left(\mathrm{q}_{1}\right)$ among parents. In

${ }^{4}$ The percentages are computed as explained in the previous footnote. 


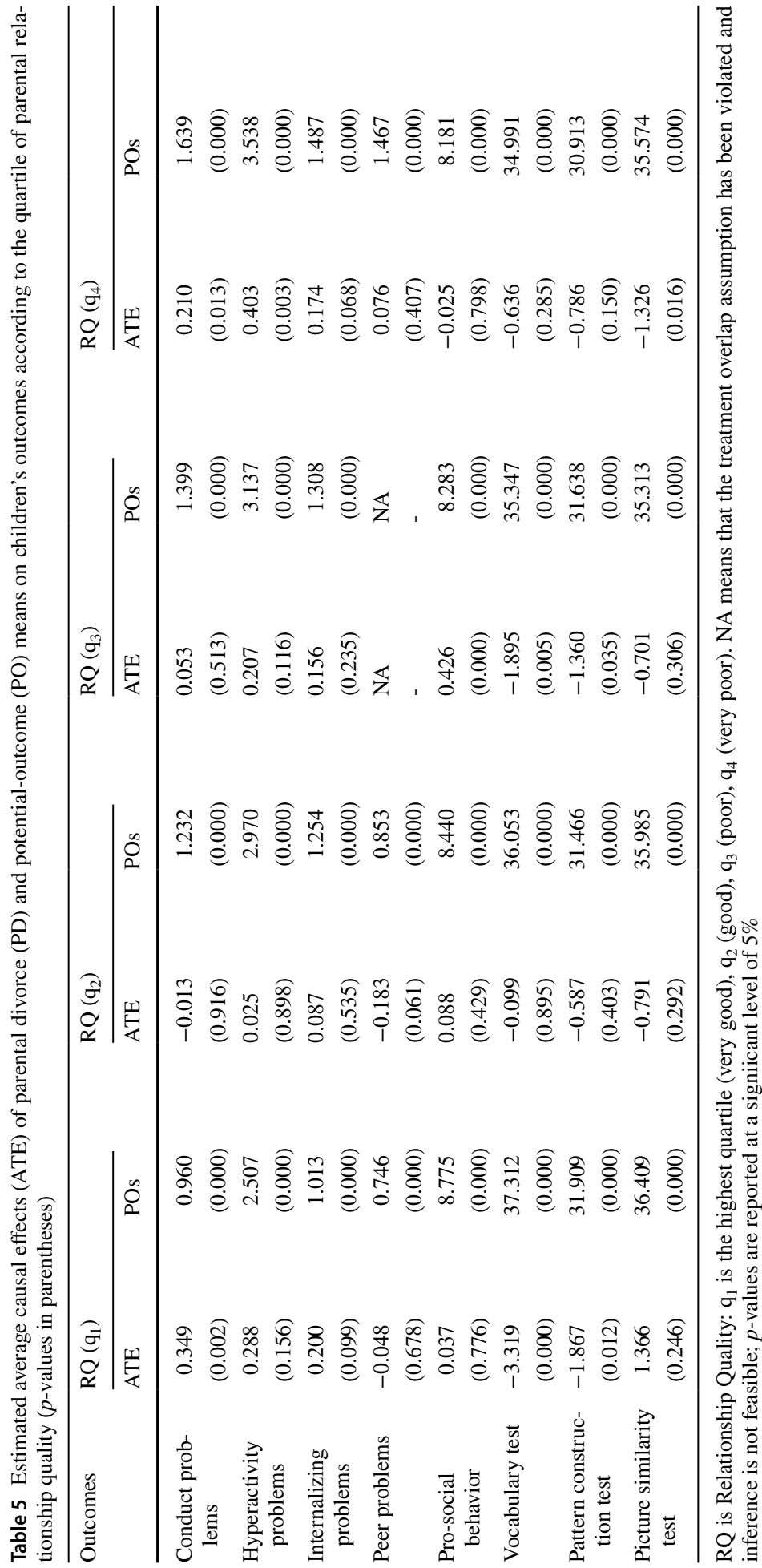


this category, parental divorce decreases the score of the vocabulary test by an average of 3.319 points. It is also significant but lower in magnitude for those whose parents had a bad relationship $\left(\mathrm{q}_{3}\right)$. For the pattern construction test the estimated ATE is significant and negative for children experiencing poor and very poor relationships.

\section{Discussion}

This work is an attempt to elucidate the interrelationships between family disruption and parental relationship quality by testing the following three main hypotheses: $i$ ) parental relationship quality and family disruption are unrelated processes that have independent effects on children (the independent hypothesis); $i$ ) the apparent effect of family disruption is explained according to the parental relationship quality (the selection hypothesis); iii) the effect of family disruption on children depends on the quality of the parental relationship (the heterogeneity hypothesis).

We advance previous research in several ways. First, we evaluate the importance of these hypotheses using a comprehensive view of child development rather than focusing on a single outcome. We analyze multiple domains of children's school readiness: cognitive and psychological well-being. Second, we focus on very young children who are at a key point in their development, namely the transition to school, while most research focuses on children in middle childhood or older. Third, we also analyze parental temporary separation which is a type of family disruption that is only scarcely covered in previous literature. Fourth, unlike most previous research, our study examines the heterogeneity of divorce effects by parental relationship quality outside of the US by using a UK nationally representative sample. Fifth, we use a proper multivariate method to impute the missing values and we employ the augmented inverse propensity treatment weighted estimator to infer the causal effects in each imputed dataset and we combine the results. Up to our knowledge this estimator has not been used by previous studies to assess the effect of parental divorce on children well-being.

We find mixed support for the $i$ ) independent and the $i$ ) selection hypotheses, obtaining a different pattern for each outcome and type of family disruption. The selection hypothesis is supported by the potential outcome models regarding the average effect of parental divorce on pro-social behavior, internalizing and peer problems. Nevertheless, there is evidence in favor of the independent hypothesis in five of the eight outcomes.

Parental temporary separation only has a significant effect on conduct and hyperactivity problems; however, the magnitude of the effect of this type of family disruption is greater than the magnitude of the effect of divorce. These results indicate that, although children experiencing parental temporary separation have been invisible in most previous research and family policies, they are also at risk, and more research on this type of family disruption is needed (Nepomnyaschy and Teitler 2013; Halpern-Meekin and Turney 2016).

With regard to the third hypothesis related to the heterogeneity of divorce effects, this study shows that the average independent effects mask the substantial variation of the effect of parental divorce. First, we find that a non-negligible proportion of children from divorced families did not experience parental relationship problems. For this group of children, the idea that the negative effects of parental divorce are explained by parental relationship quality is not valid. In addition, our findings clearly support the hypothesis that the dissolution of high-quality parental unions has the most harmful effects on children's lives. We find that among children whose parents had a very good relationship quality, there are 
substantial differences between those whose parents divorce and those that remain together in six of the eight analyzed dimensions. In four outcomes, the effect of parental divorce is greater for them with respect to the others.

Our findings for children of non-distressed families are in accordance with the existing literature on the heterogeneity of divorce effects based on children in middle childhood, adolescence or adulthood using US and Canadian data. However, it is important to point out that our results based on children at age 5 clearly diverge from those obtained by Fomby and Osborne (2010) with children at age 3, which find that parental divorce is not harmful for children in high- and low-conflict families. This discrepancy is probably due to the fact that these authors categorize three-quarters of the unions as high-quality, while we consider of very good quality only those unions above the 75 th percentile (highest relationship quality) of the sample distribution. This result is consistent with research on the heterogeneity of divorce effects in adults which shows that divorce has the most harmful emotional effects among those who had satisfactory relationships prior to separation. Therefore, it is reasonable to assume that the children of these parents, especially the very young, are also affected more strongly.

We do not find any evidence that corroborates the hypothesis that the effect of parental divorce is positive for children who experienced poor parental relationship quality (see also Booth and Amato 2001; Hanson 1999). It is also important to acknowledge that we do not expect to obtain this finding in a country such as the UK where fewer children are living in poor families compared to the US (OECD 2017). Comparative research on the heterogeneity of the effects of parental divorce is needed in order to determine to what extent this hypothesis varies by country and the mechanisms that may explain this variation such as the generosity of family policies.

In addition to that, we explain why we find a divergence between our result and the one obtained by previous studies. First, as mentioned, these studies have used a continuous measure of parental relationship quality and they consider the interaction effect between parental divorce and parental relationship quality instead we evaluate to what extent the effect of divorce differs between very good, good, poor and very poor relationship quality. This allow us to detect a non-linear pattern in some of our outcomes: children whose parental relationship lay in the extremes (very good or very poor) are those most affected by divorce while children whose parental relationship was moderately good or bad are the least affected. Making a comparison with adult data, our results are in line with the findings of Williams (2003). Second, the proposed model specification based on the augmented inverse probability weighted estimator which requires to specify a potential outcome model along with the propensity score model, has never been proposed in this context. Third, most previous research has focused on parental conflict measured in terms of the frequency of disagreements, rather than on a measure of overall marital discord and quality, the millennium cohort study does not, however, provide a direct measure of the disagreement among parents. Also, our measure of parental relationship quality is derived from the mother's perceptions and therefore misses the father perceptions. Due to these limitations, we are not able to capture the overall level of relationship quality that children experience at home. For this reason, we cannot rule out the possibility that if we had better measures to assess disharmonious families, we may have found positive effects of parental divorce for children living in them. Future research may be improved by using more subtle measurements of relationship quality and focusing on the heterogeneity effects of divorce on very young children. 
Another reason that could explain why parental separation is not beneficial for children who experienced poor parental relationship quality is that we are not able to capture its duration. Research shows that there are different trajectories of parental relationship quality over time and that experiencing persistent poor parental relationship quality has more negative effects on children's well-being than experiencing temporary poor parental relationship quality. Hence, it is reasonable to hypothesize that parental separation can be positive for children whose parents experienced a chronically poor parental relationship quality while the same event can be damaging for children that only experienced temporary poor parental relationship quality prior to separation. An important contribution of future research would be to include the measurement of the duration and trajectories of parental relationship quality in the studies of the heterogeneity effects of parental divorce. In addition to that, future studies should not only analyze the heterogeneity effects of parental divorce but also the heterogeneity effects of other forms of family transitions such as parental temporary separation. Children experience an increase in the number and types of family dissolution experiences during childhood: parents separate and then they may get back together or have a new partner and may separate again (Amato 2010).

Overall, the present study makes two main contributions to the literature by employing a suitable model to infer causality by reporting that parental temporary separation has detrimental effects for children, and that parental divorce exerts the most harmful effects among children whose parents enjoyed a very good parental relationship quality prior to separation. Our results can be used also to define policies targeted to those children for whom the detrimental effect of divorce might be stronger.

Acknowledgements Open access funding provided by Università degli Studi di Milano - Bicocca within the CRUI-CARE Agreement. Garriga thanks the grants of the Spanish Ministry of Economy and Competitiveness (Grants CSO2012-33476 and CSO2015-69439-R). Pennoni thanks the grant "Finite mixture and latent variable models for causal inference and analysis of socio-economic data" (FIRB-Futuro in Ricerca) funded by the Italian Government (RBFR12SHVV). The authors thank Isabella Romeo for her contribution to preliminary data analyses.

Open Access This article is licensed under a Creative Commons Attribution 4.0 International License, which permits use, sharing, adaptation, distribution and reproduction in any medium or format, as long as you give appropriate credit to the original author(s) and the source, provide a link to the Creative Commons licence, and indicate if changes were made. The images or other third party material in this article are included in the article's Creative Commons licence, unless indicated otherwise in a credit line to the material. If material is not included in the article's Creative Commons licence and your intended use is not permitted by statutory regulation or exceeds the permitted use, you will need to obtain permission directly from the copyright holder. To view a copy of this licence, visit http://creativecommons.org/licenses/by/4.0/.

\section{References}

Amato, P. R. (1993). Children's adjustment to divorce: Theories, hypotheses, and empirical support. Journal of Marriage and Family, 55, 23-38.

Amato, P. R. (2010). Research on divorce: Continuing trends and new developments. Journal of Marriage and Family, 72, 650-666.

Amato, P. R., \& Hohmann-Marriott, B. (2007). A comparison of high-and low-distress marriages that end in divorce. Journal of Marriage and Family, 69, 621-638.

Amato, P. R., Loomis, L. S., \& Booth, A. (1995). Parental divorce, marital conflict, and offspring wellbeing during early adulthood. Social Forces, 73, 895-915.

Bang, H., \& Robins, J. M. (2005). Doubly robust estimation in missing data and causal inference models. Biometrics, 61, 962-973. 
Booth, A., \& Amato, P. R. (1991). Divorce and psychological stress. Journal of Health Social Behavior, 32, 396-407.

Booth, A., \& Amato, P. R. (2001). Parental predivorce relations and offspring post divorce well-being. Journal of Marriage and Family, 63, 197-212.

Brooks-Gunn, J., Han, W. J., \& Waldfogel, J. (2010). First-year maternal employment and child development in the first seven years. Monographs of the Society for Research in Child Development, 75, 7-9.

Brown, S. L. (2004). Family structure and child well-being: The significance of parental cohabitation. Journal of Marriage and Family, 66, 351-367.

Bussell, D. A. (1996). A pilot study of African American children's cognitive and emotional reactions to parental separation. Journal of Divorce and Remarriage, 24, 1-22.

Cao, W., Tsiatis, A. A., \& Davidian, M. (2009). Improving efficiency and robustness of the doubly robust estimator for a population mean with incomplete data. Biometrika, 96, 723-734.

Elliott, C. D., Smith, P., \& McCulloch, K. (1997). Technical manual British Ability Scales II. Berks: NFERNELSON Publ. Co, Windsor.

Fitzgerald, K. A. (2010). Interparental conflict and emotional in security: coparenting and parent-child relationships as mediating family processes. Masters Thesis. Western Washington University.

Fomby, P., \& Osborne, C. (2010). The influence of union instability and union quality on children's aggressive behaviour. Social Science Research, 39, 912-924.

Gähler, M., \& Palmtag, E. L. (2015). Parental divorce, psychological well-being and educational attainment: Changed experience, unchanged effect among Swedes born 1892-1991. Social Indicators Research, $123,601-623$.

Glynn, A. N., \& Quinn, K. M. (2010). An introduction to the augmented inverse propensity weighted estimator. Political Analysis, 18, 36-56.

Goodman, R. (1997). The strengths and difficulties questionnaire: A research note. Journal of Child Psychology and Psychiatry, 38, 581-586.

Graham, A. M., Fisher, P. A., \& Pfeifer, J. H. (2013). What sleeping babies hear: A functional MRI Study of interparental conflict and infants' emotion processing. Psychological Science, 24, 782-789.

Halpern-Meekin, S., \& Turney, K. (2016). Relationship churning and parenting stress among mothers and fathers. Journal of Marriage and Family, 78, 715-729.

Hansen, K., \& Joshi, H. (2007). Millennium Cohort Study second survey: A user's guide to initial findings. London: Centre for Longitudinal Study, Institute of Education.

Hansen, K., et al. (2012). Millennium Cohort Study: A guide to datasets (seventh editions). First, second, third and fourth surveys. London: Centre for Longitudinal Study, Institute of Education.

Hanson, T. L. (1999). Does parental conflict explain why divorce is negatively associated with child welfare? Social Forces, 77, 1283-1316.

Hill, V. (2005). Through the past darkly: A review of the British ability scales second edition. Child and Adolescent Mental Health, 10, 87-98.

Holland, P. W., \& Rosenbaum, P. R. (1986). Conditional association and unidimensionality in monotone latent variable models. Annals of Statistics, 14, 1523-1543.

Idstad, M., Torvik, F. A., Borren, I., Rognmo, K., Røysamb, E., \& Tambs, K. (2015). Mental distress predicts divorce over 16 years: The HUNT study. BMC Public Health, 15, 1.

Imbens, G. W., \& Wooldridge, J. M. (2009). Recent developments in the econometrics of program evaluation. Journal of Economic Literature, 47, 5-86.

Jekielek, S. M. (1998). Parental conflict, marital disruption and children's emotional well-being. Social Forces, 76, 905-936.

Kalmijn, M. (2015). How childhood circumstances moderate the long-term impact of divorce on fatherchild relationships. Journal of Marriage and Family, 77, 921-938.

Kalmijn, M., \& Monden, C. W. (2006). Are the negative effects of divorce on well-being dependent on marital quality? Journal of Marriage and Family, 68, 1197-1213.

Karraker, A., \& Latham, K. (2015). In sickness and in health? Physical illness as a risk factor for marital dissolution in later life. Journal Health and Social Behavior, 56, 420-435.

Ketende, S. (2010). MCS technical report on response. London: Centre for Longitudinal Studies.

Kiernan, K. E., \& Huerta, M. C. (2008). Economic deprivation, maternal depression, parenting and children's cognitive and emotional development in early childhood. Bristish Journal Sociology, 59, $783-806$.

Kiernan, K., McLanahan, S., Holmes, J., \& Wright, M. (2011). Fragile families in the US and UK. Centre for Research on Child Well-Being. Working Paper WP 11-04-FF, Princeton University, Princeton, NJ. 
Kiernan, K. E., \& Mensah, F. K. (2009). Poverty, maternal depression, family status and children's cognitive and behavioural development in early childhood: A longitudinal study. Journal of Social Policy, 38, 569-588.

Kim, H. S. (2011). Consequences of parental divorce for child development. American Sociological Review, 76, 487-511.

Kim, L. S., Sandler, I. N., \& Tein, J. Y. (1997). Locus of control as a stress moderator and mediator in children of divorce. Journal of Abnormal Child Psychology, 25, 145-155.

Levinger, G. (1976). A social psychological perspective on marital dissolution. Journal of Social Issues, 32, $21-47$.

Lunceford, J. K., \& Davidian, M. (2004). Stratification and weighting via the propensity score in estimation of causal treatment effects. Statistics in Medicine, 23, 2937-2960.

Maes, S. D., De Mol, J., \& Buysse, A. (2012). Children's experiences and meaning construction on parental divorce: A focus group study. Childhood, 19, 266-279.

McLanahan, S., Tach, L., \& Schneider, D. (2013). The causal effects of father absence. Annual Review of Sociology, 39, 399-427.

Morrison, D. R., \& Coiro, M. J. (1999). Parental conflict and marital disruption: Do children benefit when high-conflict marriages are dissolved? Journal of Marriage and Family, 61, 626-637.

Muluk, N. B., Bayoğlu, B., \& Anlar, B. (2014). Language development and affecting factors in 3-to 6-yearold children. European Archives of Oto-Rhino-Laryngology, 271, 871-878.

Nepomnyaschy, L., \& Teitler, J. (2013). Cyclical cohabitation among unmarried parents in fragile families. Journal of Marriage and Family, 75, 1248-1265.

Neugebauer, R., \& van der Laan, M. (2005). Why prefer double robust estimators in causal inference? Journal of Statistical Planning and Inference, 129, 405-426.

OECD. (2017). Social policy division-directorate of employment, labour and social affairs. OECD Family Database. CO2.2: Child poverty, http://www.oecd.org/els/family/database.htm. Accessed 20 April 2020.

Oláh, L. S., \& Gähler, M. (2014). Gender equality perceptions, division of paid and unpaid work, and partnership dissolution in Sweden. Social Forces, 93, 571-594.

Petterson, S. M., \& Albers, A. B. (2001). Effects of poverty and maternal depression on early child development. Child Development, 72, 1794-1813.

Plewis, I. (2007). Non-response in a birth cohort study: the case of the Millennium Cohort Study. International Journal of Social Research Methodology, 10, 325-334.

Plewis, I., Calderwood, L., Hawkes, D., Hughes, G., \& Joshi, H. (2000). Millennium Cohort Study: Technical Report on Sampling. London: Centre for Longitudinal Study, Institute of Education.

Raghunathan, T. E., Lepkowski, J. M., Van Hoewyk, J., \& Solenberger, P. (2001). A multivariate technique for multiply imputing missing values using a sequence of regression models. Survey Methodology, 27, 85-96.

Robins, J. M., Hernan, M. A., \& Brumback, B. (2000). Marginal structural models and causal inference in epidemiology. Epidemiology, 11, 550-560.

Robins, J. M., Rotnitzky, A., \& Zhao, L. P. (1994). Estimation of regression coefficients when some regressors are not always observed. Journal of American Statistical Association, 89, 846-866.

Romano, E., Babchishin, L., Pagani, L. S., \& Kohen, D. (2010). School readiness and later achievement: Replication and extension using a nationwide Canadian survey. Developmental Psychology, 46, 995-1007.

Rosenbaum, P. R. (1987). Model-based direct adjustment. Journal of the American Statistical Association, $82,387-394$.

Rosenbaum, P. R. (2020). Modern algorithms for matching in observational studies. Annual Review of Statistics and its Applications, 7, 143-176.

Rosenbaum, P. R., \& Rubin, D. (1983). The central role of the propensity score in observational studies for causal effects. Biometrika, 70, 41-55.

Rubin, D. B. (1974). Estimating causal effects of treatments in randomized and nonrandomized studies. Journal of Educational Psychology, 66, 688-701.

Rubin, D. B. (1996). Multiple imputation after 18+years. Journal of American Statistical Association, 91, 473-489.

Rubin, D. B. (2002). Introduction to multiple imputation. Stat. Anal. Missing Data, 2nd Ed NY, Wiley, pp. 85-93.

Rust, J., Bennun, I., Crowe, M., \& Golombok, S. (1990). The GRIMS: A psychometric instrument for the assessment of marital discord. Journal of Family Therapy, 12, 45-57.

Sabates, R., \& Dex, S. (2015). The impact of multiple risk factors on young children's cognitive and behavioural development. Children and Society, 29, 95-108. 
Strohschein, L. (2005). Parental divorce and child mental health trajectories. Journal of Marriage and Family, 67, 1286-1300.

Vennum, A., Lindstrom, R., Monk, J. K., \& Adams, R. (2014). "It's complicated" The continuity and correlates of cycling in cohabiting and marital relationships. Journal of Social and Personal Relationship, 31, 410-430.

Waite, L. J., Luo, Y., \& Lewin, A. C. (2009). Marital happiness and marital stability: Consequences for psychological well-being. Social Science Research, 38, 201-212.

Wheaton, B. (1990). Life transitions, role histories, and mental health. American Sociological Review, 55, 209-223.

Williams, K. (2003). Has the future of marriage arrived? A contemporary examination of gender, marriage, and psychological well-being. Journal of Health Social Behavior, 44, 470.

Wilson, S. E., \& Waddoups, S. L. (2002). Good marriages gone bad: Health mismatches as a cause of laterlife marital dissolution. Population Research Policy Review, 21, 505-533.

Ye, M., DeMaris, A., \& Longmore, M. A. (2017). Role of marital quality in explaining depressive symptoms after marital termination among older adults. Marriage Family Review, 1, 1-16.

Yu, T., Pettit, G. S., Lansford, J. E., Dodge, K. A., \& Bates, J. E. (2010). The interactive effects of marital conflict and divorce on parent-adult children's relationships. Journal of Marriage and Family, 72, 282-292.

Zhou, N., Cao, H., \& Leerkes, E. M. (2017). Interparental conflict and infants' behavior problems: The mediating role of maternal sensitivity. Journal of Family Psychology, 31, 464-474.

Publisher's Note Springer Nature remains neutral with regard to jurisdictional claims in published maps and institutional affiliations. 